\begin{tabular}{ccc}
\hline AECORDS OF PHARMACEUTICAL \\
AND BIOMEDICAL SCIENCES
\end{tabular}

\title{
Cellular Mechanism involved in cypermethrin induced neurotoxicity
}

\author{
Hafiz F.H. Ali ${ }^{a^{*}}$, Norhan M El-Sayed ${ }^{\mathrm{b}}$, Dina M khodeer ${ }^{\mathrm{b}}$, Amal A.M. Ahmed ${ }^{\mathrm{c}}$ Pierre A. Hanna $^{\mathrm{d}}$, \\ Yasser M. A. Moustafa ${ }^{b}$ \\ ${ }^{a}$ Ministry of health, Tobruk, Libya, ${ }^{b}$ Department of Pharmacology \& Toxicology, Faculty of Pharmacy, Suez \\ Canal University, Ismailia , Egypt, ${ }^{C}$ Department of Cytology and Histology, Faculty of Veterinary Medicine, \\ Suez Canal University, Ismailia, Egypt, ${ }^{d}$ Department of Pharmaceutics, Faculty of Pharmacy, Suez Canal \\ University, Ismailia, 41522, Egypt.
}

Received on: 09. 10. 2019

Revised on: 5. 12. 2019

Accepted on: 13.12. 2019

Correspondence Author:

Tel: +01100338768

E-mail address:

hafed_farhat@yahoo.com

\begin{abstract}
Cypermethrin (CYP): Is a class II synthetic pyrethroid that can cause in general irritation, itching at skin and eyes, burning sensation and loss of bladder control through ingestion or directly through dermal absorption exerts. It causes neurotoxicity passing through blood brain barrier in the central nervous system \& induces motor deficits. Cypermethrin does not only causing neurotoxicity on central nervous system, but it's also affecting the peripheral nervous system. The inhibtory effect on the $\gamma$ aminobutyric acid (GABA) receptor, causing excitability and convulsions by decreasing the calcium uptake by nerves, suppression in immune system function in rats, it showed decrease in the numbers of Natural killer NK cells and increase in serum immunoglobulins (Igs) and causes early embryonic deaths, damage in genetic material, disrupts the sexual behavior and estrous cycle disruption. Exposure to low dose of CYP didn't produce any alternation in GPx, CAT, and SOD activities. Generates proinflammatory cytokines as interleukins (IL) and tumor necrosis factor alpha (TNF- $\alpha$ ) induced by activation of microglia and astrocytes caused by cypermethrin, this activation led to increase the level of TNF- $\alpha$ and IL$1 \beta$.
\end{abstract}

Keywords: Cypermethrin, GABA, GPx, TNF- $\alpha$, IL-1 $\beta$.

\section{Introduction}

Cypermethrin is a synthetic pyrethroid pesticide which is a organic pesticide. CYP is commonly used pesticide in agriculture because it is a mixture of all eight possible chiral isomers to control ectoparasites that infest cattle, sheep, and poultry (Meyling et al., 2018). Cypermethrin is result from condensation between 3-(2,2-dichlorovinyl)-2,2-

dimethylcycloprpanecarboxlic acid and the alcoholic hydroxy group of hydro(3phenoxyphenyl)acetonitile form a carboxlic ester with IUPAC name [cyano-(3phenoxyphenyl)methyl]3-(2,2-dichloroethenyl)2,2-dimethylcyclopropane-1-carboxylate (Fig.1). 


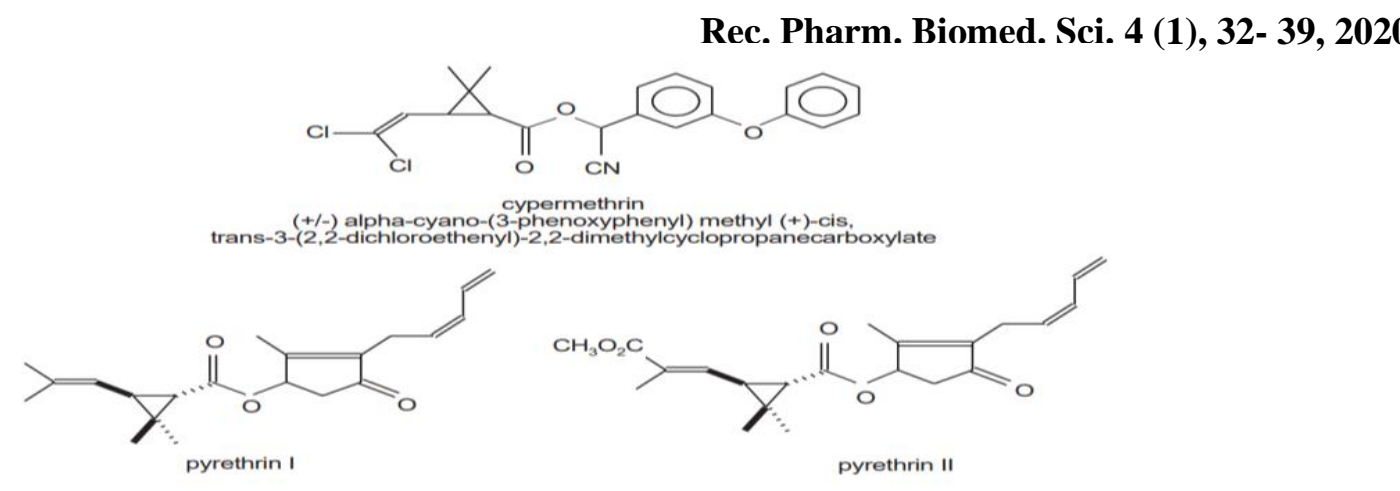

Figure (1): Cypermethrin and related naturally-occurring insecticidal chemicals (Cox, 1996).

\section{Mode of action of cypermethrin:}

All synthetic pyrethroids kill pests by interrupting the normal function of the nervous system of the pests. CYP has the same way of action like all pyrethiods (Soderlund, 2010).

The normal function of nervous system in all animals and inscects is transduction of nerve impulse. This is done by exchange in sodium and potassium ions through sodium-potassium gate (Lodish et al., 2000).

CYP delays the closure of sodium-potasium gate which allows the flow of sodium resulting in spelly the generation of multiple nerve impulses instead of the usual single one. Also, CYP has an inhibtory effect on the $\gamma$-aminobutyric acid receptor, causing excitability and convulsions by decreasing the calcium uptake by nerves. It inhibits monoamine oxidase and indirect affects adenosine triphosphatase that is involved in the cellular energy production, transport of metal atoms, and muscle contractions (Narahashi, 2010).

\section{General effects of cypermethrin:}

CYP can cause irritation, itching at skin and eyes, burning sensation and loss of bladder control through ingestion or directly through dermal absorption. Nervous and muscular system are the major parts which are affected mainly by intoxication with CYP and other synthetic pyrethroids (Rehman et al., 2014).

Effect of cypermethrin on human and expermintal animals:

Medical reports have documented that exposure of human to CYP showed facial burning, tingling, headache, nausea, fatigue and loss of bladder control. Exposure to higher dose leads to muscle twitching, drowsiness, coma, and seizures. Expermintal data on laboratory animals has reported that exposure to CYP showed pawing, burrowing, salivation, tremors, writhing, and seizures (Alwan, 2015).

Effect of cypermethrin on the immune system:

Previous studies showed that suppression in immune system function in both rats and rabbits treated with CYP (Wang et al., 2017; Ambwani et al., 2018). Aroonvilairat et al.,(2018) reported that dermal exposure to CYP showed decrease in the numbers of NK cells and increase in serum immunoglobulins (Igs). Earlier studies has reported that CYP decreases both humoral and cellular immune responses in rats and rabbits (Allam et al., 2016; Iteire et al., 2017).

\section{Effect of cypermethrin on reproduction:}

Exposure to cypermethrin can effect pregnant experimental animals and their offspring. Several studies has showed that exposure of pregnant female to CYP causes early embryonic deaths, disrupts the sexual behavior and estrous cycle disruption. It adversely affects the progesterone production in bovines (Gill $\boldsymbol{e t}$ al., 2011; Sangha et al., 2013; Sallam et al., 2015). Also, male reproductive system is affected by CYP. Treatment with CYP in rats caused decreases in the ejaculate volume, sperm concentration, sperm motility, semen initial fructose and plasma testosterone (Alaa-Eldin et al., 2017). A study has shown that inhibition of testostrone receptor in testes by CYP indicates disturbance of sex hormones (Sharma $\boldsymbol{e t}$ al., 2018).

\section{Effect of cypermethrin on Mutagenicity:}

Researches on laboratory animals have shown that CYP caused damage in genetic material. It was demonstrated that CYP induces DNA damage in vital organs such as brain, liver and kidney (Patel et al., 2006). Injection of CYP to mice leads to abnormal chromosomes in both bone marrow and spleen (Queiroz et al., 2013). 


\section{Carcinogenicity of cypermethrin:}

CYP is classified as human carcinogen according to EPA. A study have demonstrated that CYP cause lung tumor in mice (Sheikh et al., 2014).

The molecular mechanism of CYP casuing cancer may be fristly by gap junction intercellualr communication that important in cell growth and differentiation, secondly by also increased the number of altered foci (George and Shukla, 2011).

\section{Other chronic effects of cypermethrin:}

Long-term feeding with CYP in rats, mice and dogs showed redetion in the growth rate, increased liver weight, mild anemia, loss of appetite, incoordination, and tremors (Baharuddin et al., 2016). Administration of CYP orally for 21 days showed haemorrhage, congestion with focal myolysis disruption in branching structure, with loss of striations, and early necrotic changes in the myocardium of rats (Nair et al., 2011).

\section{Effect of cypermethrin on nervous system:}

CYP-induced neurotoxicity is indeed a matter of apprehension because the neurotoxicity effect of cypermethrin has not well-documented. Neurotoxicity of cypermethrin depend on doses, time and route of exposure that produce a variety of clinical neurotoxic effects such as tremors, paresthesia, splayed gait, paresthesia and depression (Kumar Singh et al., 2012).

Prevoius data reported that human exposure to $10 \%$ CYP solution causes death after 3 hours (Wang et al., 2016). CYP is causes neurotoxicity passing through blood brain barrier in the central nervous system to induce motor deficits. CYP not only cause neurotoxicity on central nervous system but also on the peripheral nervous system. A report showed preformed on CYP induced neurotoxicity in expermintal animals and reported that CYP implicated in Parkinson's disease (PD) pathogenesis (Baltazar et al., 2014). A study performed on albino rats reproted that oral administation of CYP at $(14.5 \mathrm{mg} / \mathrm{kg}$ b.w) induced neurotoixity in the cerebellum of exposed rats through disturbance in neurotransimetters such as gamma-aminobutyric acid (GABA), dopamine and acetylcholinesterase (Elsawy et al., 2017). A report showed that CYP antagonizes GABA. A study has found that down reuglation in GABA concentration in the brain of experimental animals after expouse to a high dose of CYP (Anantharam et al., 2017). Administration of high dose of CYP induced the reduction in serotonin level in the frontal cortex of experimental animals (Anshuman Singh et al., 2016). CYP nduced decrease in acetyl- and butyryl- cholinesterase activities at high doses, however at low dose it didn't produced alteration in activities of acetyl- and butyryl-cholinesterase (Rani et al., 2017). A report demonstrated the adverse effect of cypermethrin includes nigrostriatal dopaminergic neurotoxicity through mitochondrial dysfunction (Agrawal et al., 2015).

Several evidence reported that chronic exposure of rats or human to cypermethrin showed epileptic activity and behavioral anomalies (GómezGiménez et al., 2017; Ganie et al., 2018).

Behavior studies on expermintal animals exposed to cypermethrin showed sequence of visible motor symptoms along with chewing, stayed limbs, increased foot splay, reduced arousal and reduced response to touch pinches (Rashkivska et al., 2017).

\section{Mechanism of cypermethrin induced neurotoxicity:}

A study has documented that the neurotoxicity mechanism of all pyrethroids targets the sodium and magnesium channels. Few reports stated that chemically alternation of CYP so it become an axonic posion. CYP is always used with pepperoni butoxide (PBO) that acts as synergist by enhancing the effect of cyermethrin through inhibiting cytochrome P450 enzyme (Sharma et al.,2018).

CYP induced neurotoxicity is through changing in the voltage gate of sodium channel. Voltage-gated channels composed of $1 \alpha$ and $2 \beta$ subunits in mammalian cells. CYP causes a stable hyperexcitable state through binding to subunits of sodium channel to prevent channel from closing that cause continuous nerve stimulation (Khan et al., 2018).

CYP also targets calcium and chloride channels that lead to distinct toxic syndromes. CYP causes inhibition of voltage-gated calcium channel (VGCC) by alters the kinetics and calcium influx that regulates the protein kinases and phosphatases. These enzymes are involved in the signal transduction pathways. CYP is a strong inhibitor of calcineurin that alters $\mathrm{Ca}^{2+}$ influx leading to decrese in calcium level and release of neurotransmitter (Hernández et al., 2017).

Previous studies reported that administration of 
CYP at lower concentration didn't induced any effect, however, at high concentration induced delay in phosphorylation of calcineurin and inhibition of calcium channel (Hernández et al., 2017; Meijer et al., 2015; Li et al., 2017).

As CYP induced inhibition in calcium channel, it causes defect in potasium channels that regulate excitability of neurons. In constract reports demonstrated that administration of CYP at lower level cause retardation in the function of potassium channels and at higher concentrations, it inactivates the potassium current (Cao et al., 2011).

GABA is a dominant neurotransmitter that regulates chloride channels in brain. CYP represses the voltage-gated chloride channels opening and inhibits GABA dependent uptake of chloride ions. The change in homeostasis of chloride channels leads to hyper-excitability and neurotoxicity. Inhibtion of chloride channel induced by

CYP produces minor tremors, depression, hyperesthesia, and spastic paralysis depending on the exposure dose (Ch et al., 2015).

Burgeoning evidence has documented that cypermethrin induced neurotoxicity is closely correlated with oxidative stress. Oxidative stress resulting from reactive oxygen species (ROS) and reactive nitrogen species production. The brain is very sensitive to oxidative stress due the inhibition of enzymatic antioxidant activities caused by cypermethrin. The oxidative stress induced by cypermethrin might be dose-dependent (Agrawal et al., 2015).

A report has documented that CYP could decrease the enzymatic antioxidant system that leads to cellular damage in lipids, protiens and DNA. Oxidative stress occurred by CYP results in cell death via apoptotic or necrotic mechanisms. DNA damage, enhanced lipid peroxidation and protein damage may occur during cell death process (Ashish Singh et al., 2016).

Lipid peroxidation induced by oxidative stress can be measured the end products of lipid peroxidation such as malondialdehyde (MDA) and thiobarbituric acid reacting substances (TBARS). Malondialdehyde reflects the degradation of neuronal membrane. Study of CYP-induced oxidative stress in rats showed increased levels of MDA in brain tissue. More than 50\% of brain weight is made up of lipids, and the membranes of nerve cells are rich in polyunsaturated fatty acids
(PUFAs). Lipid peroxidation leads to loss of membrane fluidity and potential difference, thereby increasing the permeability. Many publications reported that the elevation of lipid peroxidation induced by CYP is shown in different brain regions such as hippocampus and cortex (Kaushik, 2018; Mu et al., 2017).

Oxidative stress also targets protein as well as lipids, this can be detected by protein carbonyls (PC) resulted from oxidation of proteins. A study in-vitro and in-vivo has documented that significant increases in PC resulted by CYP administration (Hocine et al., 2016).

Recent study performed on rats demonstrated that exposure to high doses of CYP generate ROS represented in elevation of $\mathrm{PC}$ concentration in the brain tissue (Elhalwagy et al., 2018).

It was shown indicated that enzymatic antioxidant system affected by exposure to CYP. CYP administration decreases the CAT, SOD and GPX activities in rats (Sharma et al., 2014).

Epidemiological studies reported that SOD has found in lower concentration in the brain with different doses of CYP (Eraslan et al., 2016).

Increase ROS due to exposure of CYP indicate that increase level of $\mathrm{H}_{2} \mathrm{O}_{2}$ with decrease CAT activity. Exposure to low dose of CYP didn't produce any alternation in GPx, CAT, and SOD activities, indicating that CYP had a dose-dependent effect on antioxidant enzymes. Recently, in a study to reveal the effect of CYP on rats, CYP led to decrease in GPx, GSH and GST activities. A recent study suggested that CYP and its metabolites, induce deformational in SOD (MANSOUR et al., 2018).

Apoptosis is a process of programmed cell death that is essential for development and tissue homeostasis (Nagata and Tanaka, 2017). Previous study has been suggested that at the neuronal death caused by CYP is due to apoptosis (Özdemir et al., 2018). It was shown documented that apoptosis in the brain is due to oxidative stress induced by cypermethrin (Paravani et al., 2018).

Exposure to CYP at high dose or at low dose causes damage in DNA that reduces nuclear divisions. Earlier studyperformed on female rats were orally treated with cypermethrin showed that increased TBARS, and decreased GSH and the activities of the antioxidant enzymes this led to DNA damage (Kalra, 2018). 


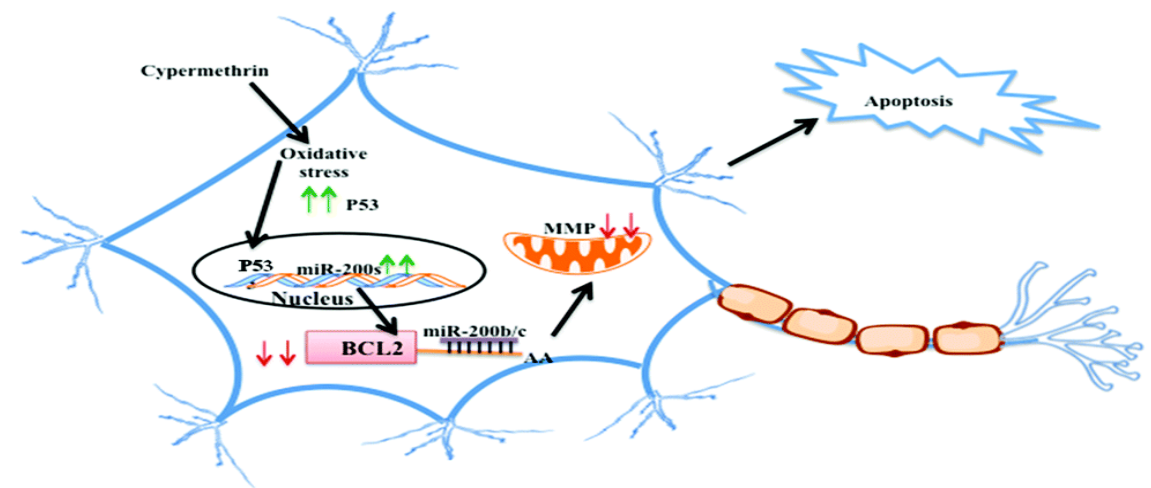

Figure (2): A schematic presentation of the role of the miR-200 family in cypermethrin-induced apoptosis of NGF differentiated PC12 cells. Double green upward arrows indicate induction, while double red arrows indicate a down-regulation in gene expression (Pandey et al., 2015).

The main key-players involved in neuroinflammation process induced by cypermethrin are microglia and astrocytes as demonstrated in many publications (GómezGiménez et al., 2017; Cankaya et al., 2019).

\section{Reference:}

Agrawal, S., Singh, A., Tripathi, P., Mishra, M., Singh, P.K., Singh, M.P., 2015. Cypermethrininduced nigrostriatal dopaminergic neurodegeneration alters the mitochondrial function: a proteomics study. Molecular neurobiology 51, 448-465.

Alaa-Eldin, E.A., El-Shafei, D.A., Abouhashem, N.S., 2017. Individual and combined effect of chlorpyrifos and cypermethrin on reproductive system of adult male albino rats. Environmental Science and Pollution Research 24, 1532-1543.

Allam, T.S., Saleh, N.S., Ghazy, E.W., Abd ElLatif, A.S., 2016. Effects of Sublethal Doses of Lampcon ${ }^{\circledR}$ and Saturn ${ }^{\circledR}$ Pesticides on Some Clinicopathological and Immunological Parameters in Rats. Alexandria Journal for Veterinary Sciences 48.

Alwan, A.K., 2015. Toxic Effects of Cypermethrin on Liver and Kidney of Male Domestic Rabbits. Toxic Effects of Cypermethrin on Liver and Kidney of Male Domestic Rabbits.

Ambwani, S., Ambwani, T.K., Singh, R., 2018. Immunotoxic effects of cypermethrin in mitogen stimulated chicken lymphocytes due to oxidative stress and apoptosis.

Anantharam, P., Whitley, E.M., Mahama, B., Kim, D.-S., Imerman, P.M., Shao, D., Langley, M.R.,
Generation of proinflammatory cytokines as interleukins (IL) and tumor necrosis factor alpha (TNF- $\alpha$ ) induced by activation of microglia and astrocytes caused by cypermethrin, this activation led to increase the level of TNF- $\alpha$ and IL-1 $\beta$ (Vardavas et al., 2016).

Kanthasamy, A., Rumbeiha, W.K., 2017. Characterizing a mouse model for evaluation of countermeasures against hydrogen sulfide-induced neurotoxicity and neurological sequelae. Annals of the New York Academy of Sciences 1400, 46.

Aroonvilairat, S., Tangjarukij, C., Sornprachum, T., Chaisuriya, P., Siwadune, T., Ratanabanangkoon, K., 2018. Effects of topical exposure to a mixture of chlorpyrifos, cypermethrin and captan on the hematological and immunological systems in male Wistar rats. Environmental toxicology and pharmacology 59, 53-60.

Baharuddin, K.A., Fauzi, M.H., Yazid, M.B., Ahmad, M.Z., Zain, W.H.W., 2016. SEVERE ACUTE POISONING BY INTENTIONAL SELFHARM WITH CYPERMETHRIN. Malaysian Journal of Emergency Medicine 1, 24-39.

Baltazar, M.T., Dinis-Oliveira, R.J., de Lourdes Bastos, M., Tsatsakis, A.M., Duarte, J.A., Carvalho, F., 2014. Pesticides exposure as etiological factors of Parkinson's disease and other neurodegenerative diseases - $\mathrm{a}$ mechanistic approach. Toxicology letters 230, 85-103.

Cankaya, S., Cankaya, B., Kilic, U., Kilic, E., Yulug, B., 2019. The therapeutic role of minocycline in Parkinson's disease. Drugs in context 8 . 
Cao, Z., Shafer, T.J., Murray, T.F., 2011. Mechanisms of pyrethroid insecticide-induced stimulation of calcium influx in neocortical neurons. Journal of Pharmacology and Experimental Therapeutics 336, 197-205.

Ch, R., Singh, A.K., Pandey, P., Saxena, P.N., Mudiam, M.K.R., 2015. Identifying the metabolic perturbations in earthworm induced by cypermethrin using gas chromatography-mass spectrometry based metabolomics. Scientific reports 5,15674 .

Cox, C., 1996. Insecticide factsheet, Cypermethrin. J. Pesticide Reform. 16, 15-20.

Elhalwagy, M.E., Nahas, A.A., Ziada, R.M., Farid, H.E., n.d. Potential Effect of Vitamin $\mathrm{C}$ and Curcumin on Oxidative Stress and Skin Lesion Induced by Dermal Intoxication with Cypermethrin.

Elsawy, H., Al-Omair, M.A., Sedky, A., Al-Otaibi, L., 2017. Protective effect of $\alpha$-lipoic acid against $\alpha$-cypermethrin-induced changes in rat cerebellum. Journal of chemical neuroanatomy $86,52-58$.

Eraslan, G., Kanbur, M., Siliğ, Y., Karabacak, M., Soyer Sarica, Z., Şahin, S., 2016. The acute and chronic toxic effect of cypermethrin, propetamphos, and their combinations in rats. Environmental toxicology 31, 1415-1429.

Ganie, P.A., Yousuf, D.J., Bhat, R.A.H., Bhat, I.A., Kunal, K., Pandey, P.K., Sarma, D., 2018. Investigation of acute toxicity and behavioral response of Indian major carp, Cirrhinus mrigala (Hamilton, 1822) in response to Cypermethrin (25\% $\mathrm{EC})$.

George, J., Shukla, Y., 2011. Pesticides and cancer: insights into toxicoproteomic-based findings. Journal of proteomics 74, 2713-2722.

Gómez-Giménez, B., Llansola, M., Cabrera-Pastor, A., Hernández-Rabaza, V., Agustí, A., Felipo, V., 2017. Endosulfan and Cypermethrin Pesticide Mixture Induces Synergistic or Antagonistic Effects on Developmental Exposed Rats Depending on the Analyzed Behavioral or Neurochemical End Points. ACS chemical neuroscience 9, 369-380.

Hernández, A.F., Gil, F., Lacasaña, M., 2017. Toxicological interactions of pesticide mixtures: an update. Archives of toxicology 91, 3211-3223.

Hocine, L., Merzouk, H., Merzouk, S.A., Ghorzi, H., Youbi, M., Narce, M., 2016. The effects of alpha-cypermethrin exposure on biochemical and redox parameters in pregnant rats and their newborns. Pesticide biochemistry and physiology 134, 49-54.

Iteire, K.A., Igbigbi, P.S., Oyibororho, O., 2017. Toxicological Effects of Pyrethroids Insecticide on the Spleen and Bone Marrow of Adult Albino Rats. Nigerian Journal of Basic and Applied Sciences 25, 143-150.

Kalra, S., 2018. Biological monitoring in cypermethrin induced albino rats (PhD Thesis). Punjab Agricultural University, Ludhiana.

Kaushik, D., 2018. Attenuating effects of ascorbic acid on cypermethrin induced histological and biochemical changes in developing brain of Gallus domesticus. Journal of Pharmacognosy and Phytochemistry $7,1108-1112$.

Khan, J., Salhotra, S., Ahmad, S., Sharma, S., Abdi, S.A.H., Banerjee, B.D., Parvez, S., Gupta, S., Raisuddin, S., 2018. The protective effect of $\alpha$ lipoic acid against bisphenol A-induced neurobehavioral toxicity. Neurochemistry international 118, 166-175.

Kumar Singh, A., Nath Tiwari, M., Prakash, O., Pratap Singh, M., 2012. A current review of cypermethrin-induced neurotoxicity and nigrostriatal dopaminergic neurodegeneration. Current neuropharmacology 10, 64-71.

Li, F., Ma, H., Liu, J., 2017. Pyrethroid insecticide cypermethrin modulates gonadotropin synthesis via calcium homeostasis and ERK1/2 signaling in L $\beta$ T2 mouse pituitary cells. Toxicological Sciences $162,43-52$.

Lodish, H., Berk, A., Zipursky, S.L., Matsudaira, P., Baltimore, D., Darnell, J., 2000. The action potential and conduction of electric impulses, in: Molecular Cell Biology. 4th Edition. WH Freeman.

MANSOUR, S.A., MOHAMED, R.I., ALI, A.R., FARRAG, A.-R.H., 2018. THE PROTECTIVE EFFECT OF MORINGA TEA AGAINST CYPERMETHRIN-INDUCED HEPATORENAL DYSFUNCTION, OXIDATIVE STRESS, AND HISTOPATHOLOGICAL ALTERATIONS IN FEMALE RATS. Asian J Pharm Clin Res 11, 111117.

Meijer, M., Brandsema, J.A., Nieuwenhuis, D., Wijnolts, F.M., Dingemans, M.M., Westerink, R.H., 2015. Inhibition of voltage-gated calcium 
channels after subchronic and repeated exposure of PC12 cells to different classes of insecticides. Toxicological Sciences 147, 607-617.

Meyling, N.V., Arthur, S., Pedersen, K.E., Dhakal, S., Cedergreen, N., Fredensborg, B.L., 2018. Implications of sequence and timing of exposure for synergy between the pyrethroid insecticide alphacypermethrin and the entomopathogenic fungus Beauveria bassiana. Pest management science 74 , 2488-2495.

Mu, X., Shen, G., Huang, Y., Luo, J., Zhu, L., Qi, S., Li, Y., Wang, C., Li, X., 2017. The enantioselective toxicity and oxidative stress of beta-cypermethrin on zebrafish. Environmental Pollution 229, 312-320.

Nagata, S., Tanaka, M., 2017. Programmed cell death and the immune system. Nature Reviews Immunology 17, 333 .

Nair, R.R., Abraham, M.J., Lalithakunjamma, C.R., Nair, N.D., Aravindakshan, C.M., 2011. A pathomorphological study of the sublethal toxicity of cypermethrin in Sprague Dawley rats. International journal of nutrition, pharmacology, neurological diseases 1,179 .

Narahashi, T., 2010. Neurophysiological effects of insecticides, in: Hayes' Handbook of Pesticide Toxicology. Elsevier, pp. 799-817.

Özdemir, S., Altun, S., Özkaraca, M., Ghosi, A., Toraman, E., Arslan, H., 2018. Cypermethrin, chlorpyrifos, deltamethrin, and imidacloprid exposure up-regulates the mRNA and protein levels of bdnf and c-fos in the brain of adult zebrafish (Danio rerio). Chemosphere 203, 318-326.

Pandey, A., Jauhari, A., Singh, T., Singh, P., Singh, N., Srivastava, A.K., Khan, F., Pant, A.B., Parmar, D., Yadav, S., 2015. Transactivation of P53 by cypermethrin induced miR-200 and apoptosis in neuronal cells. Toxicology Research 4, 1578-1586.

Paravani, E.V., Simoniello, M.F., Poletta, G.L., Zolessi, F.R., Casco, V.H., 2018. Cypermethrin: Oxidative stress and genotoxicity in retinal cells of the adult zebrafish. Mutation Research/Genetic Toxicology and Environmental Mutagenesis 826, 25-32.

Patel, S., Pandey, A.K., Bajpayee, M., Parmar, D., Dhawan, A., 2006. Cypermethrin-induced DNA damage in organs and tissues of the mouse: evidence from the comet assay. Mutation
Research/Genetic Toxicology and Environmental Mutagenesis 607, 176-183.

Queiroz, F.M. de, Matias, K.W. de O., Cunha, M.M.F. da, Schwarz, A., 2013. Evaluation of (anti) genotoxic activities of Phyllanthus niruri L. in rat bone marrow using the micronucleus test. Brazilian Journal of Pharmaceutical Sciences 49, 135-148.

Rani, M., Gupta, R.K., Yadav, J., Kumar, S., 2017. Assessment of organophosphates induced acetylcholinesterase inhibition in Indian major carps. Journal of Entomology and Zoological studies 5, 1369-1371.

Rashkivska, I., Prodanchuk, M., Kornuta, N., Zinovieva, M., 2017. Pre-and postnatal cypermethrin exposure in rats causes persistent behavioral alterations. Toxicology Letters 280, S149.

Rehman, H., Aziz, A.-T., Saggu, S.H., Abbas, Z.K., Mohan, A., Ansari, A.A., 2014. Systematic review on pyrethroid toxicity with special reference to deltamethrin. Journal of Entomology and Zoology Studies 2, 60-70.

Sallam, M.A., Ahmad, M., Ahmad, I., Gul, S.T., Idrees, M., Bashir, M.I., Zubair, M., 2015. Toxic effects of cypermethrin on the reproductive functions of female rabbits and their amelioration with vitamin $\mathrm{E}$ and selenium. Pak Vet J 35, 193 196.

Sangha, G.K., Kaur, K., Khera, K.S., 2013. Cypermethrin induced pathological and biochemical changes in reproductive organs of female rats. Journal of environmental biology 34, 99.

Sharma, A., Yadav, Bhuvnesh, Rohatgi, S., Yadav, Baljeet, n.d. Cypermethrin Toxicity: A Review.

Sharma, P., Huq, A.U., Singh, R., 2014. Cypermethrin-induced reproductive toxicity in the rat is prevented by resveratrol. Journal of human reproductive sciences 7,99 .

Sharma, P., Khan, I.A., Singh, R., 2018. Curcumin and quercetin ameliorated cypermethrin and deltamethrin-induced reproductive system impairment in male wistar rats by upregulating the activity of pituitary-gonadal hormones and steroidogenic enzymes. International journal of fertility \& sterility 12,72 .

SHEIKH, N., JAVED, S., ASMATULLAH, A., 
AHMAD, K.R., ABBAS, T., IQBAL, J., 2014. Histological changes in the lung and liver tissues in mice exposed to pyrethroid inhalation. Walailak Journal of Science and Technology (WJST) 11, 843-849.

Singh, Anshuman, Mudawal, A., Maurya, P., Jain, R., Nair, S., Shukla, R.K., Yadav, S., Singh, D., Khanna, V.K., Chaturvedi, R.K., 2016. Prenatal exposure of cypermethrin induces similar alterations in xenobiotic-metabolizing cytochrome P450s and rate-limiting enzymes of neurotransmitter synthesis in brain regions of rat offsprings during postnatal development. Molecular neurobiology 53, 3670-3689.

Singh, Ashish, Tripathi, P., Prakash, O., Singh, M.P., 2016. Ibuprofen abates cypermethrin-induced expression of pro-inflammatory mediators and mitogen-activated protein kinases and averts the nigrostriatal dopaminergic neurodegeneration. Molecular neurobiology 53, 6849-6858.

Soderlund, D.M., 2010. Toxicology and mode of action of pyrethroid insecticides, in: Hayes'
Handbook of Pesticide Toxicology. Elsevier, pp. $1665-1686$.

Vardavas, A.I., Stivaktakis, P.D., Tzatzarakis, M.N., Fragkiadaki, P., Vasilaki, F., Tzardi, M., Datseri, G., Tsiaoussis, J., Alegakis, A.K., Tsitsimpikou, C., 2016. Long-term exposure to cypermethrin and piperonyl butoxide cause liver and kidney inflammation and induce genotoxicity in New Zealand white male rabbits. Food and chemical toxicology 94, 250-259.

Wang, X., He, B., Kong, B., Wei, L., Wang, R., Zhou, C., Shao, Y., Lin, J., Jin, Y., Fu, Z., 2017. $\beta$ Cypermethrin and its metabolite 3-phenoxybenzoic acid exhibit immunotoxicity in murine macrophages. Acta biochimica et biophysica Sinica 49, 1083-1091.

Wang, X., Martínez, M.-A., Dai, M., Chen, D., Ares, I., Romero, A., Castellano, V., Martínez, M., Rodríguez, J.L., Martínez-Larrañaga, M.-R., 2016. Permethrin-induced oxidative stress and toxicity and metabolism. A review. Environmental research 149, 86-104. 